\title{
Simulating Perforation Permeability Damage and Cleanup
}

J.P. Morris, I.N. Lomov, L.A. Glenn

\section{December 15, 2000}

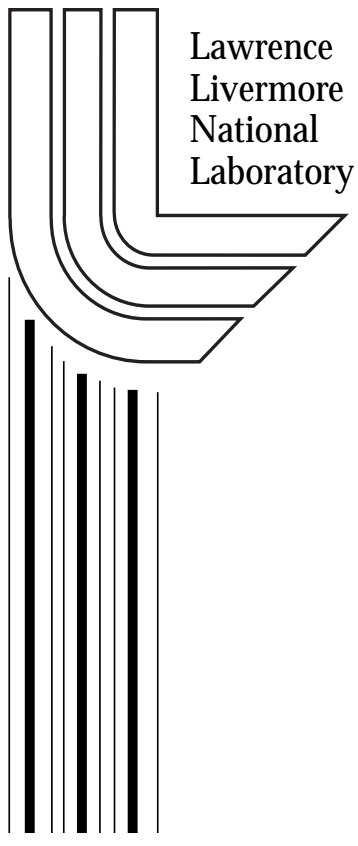




\section{DISCLAIMER}

This document was prepared as an account of work sponsored by an agency of the United States Government. Neither the United States Government nor the University of California nor any of their employees, makes any warranty, express or implied, or assumes any legal liability or responsibility for the accuracy, completeness, or usefulness of any information, apparatus, product, or process disclosed, or represents that its use would not infringe privately owned rights. Reference herein to any specific commercial product, process, or service by trade name, trademark, manufacturer, or otherwise, does not necessarily constitute or imply its endorsement, recommendation, or favoring by the United States Government or the University of California. The views and opinions of authors expressed herein do not necessarily state or reflect those of the United States Government or the University of California, and shall not be used for advertising or product endorsement purposes.

This work was performed under the auspices of the U. S. Department of Energy by the University of California, Lawrence Livermore National Laboratory under Contract No. W-7405-Eng-48.

This report has been reproduced directly from the best available copy.

Available electronically at http://www.doc.gov/bridge

Available for a processing fee to U.S. Department of Energy

And its contractors in paper from

U.S. Department of Energy

Office of Scientific and Technical Information

P.O. Box 62

Oak Ridge, TN 37831-0062

Telephone: (865) 576-8401

Facsimile: (865) 576-5728

E-mail: reports@adonis.osti.gov

Available for the sale to the public from

U.S. Department of Commerce

National Technical Information Service

5285 Port Royal Road

Springfield, VA 22161

Telephone: (800) 553-6847

Facsimile: (703) 605-6900

E-mail: orders@ntis.fedworld.gov

Online ordering: http://www.ntis.gov/ordering.htm

OR

Lawrence Livermore National Laboratory

Technical Information Department's Digital Library

http://www.llnl.gov/tid/Library.html 


\title{
SPE 00000
}

\section{Simulating Perforation Permeability Damage and Cleanup}

\author{
J. P. Morris, I. N. Lomov, and L. A. Glenn, Lawrence Livermore National Laboratory
}

\section{ABSTRACT}

Completion of cased and cemented wells by shaped charge perforation causes its own damage to the formation, potentially reducing well productivity. In practice it is found that underbalance conditions clean up the damaged zone to some extent, however, the mechanisms of these processes are poorly understood. Most hydrocodes typically used to simulate rock response to shaped charge penetration do not provide permeability estimates. Furthermore, the time scales for formation clean up are potentially much longer than the period of jet penetration. We have developed a simple, yet accurate model for the evolution of porosity and permeability which can easily be incorporated into existing hydrocodes using information from the history of each cell. In addition, we have developed a code that efficiently simulates fines migration during the post-shot surge period using initial conditions taken directly from hydrocode simulations of jet penetration. Results from a one-dimensional model simulation are in excellent agreement with measured permeability distributions. We also present two-dimensional numerical results which qualitatively reproduce experimentally obtained permeability maps for different values of underbalance. Although initial results have been promising, further comparison with experiment is essential to tune the coupling between the hydrocode and fines migration simulator. Currently the permeability model is most appropriate for high permeability sandstones (such as Berea), but with little effort, the model can be extended to other rock types, given sufficient experimental data.

\section{INTRODUCTION}

Shaped charge perforation is a field proven technique for completion of cased and cemented wells. The perforating process, however, causes its own damage to the formation, potentially reducing well productivity. In practice it is found that this damaged zone is somewhat cleaned up if the pressure in the wellbore is set lower than the formation prior to perforation. However, the mechanisms of the damage and clean-up processes are poorly understood.

Optimization of perforation performance requires a capability to predict the influence of various shaped-charge parameters (underbalance, overbalance, and liner and charge design) upon post-perforation permeability. Most hydrocodes typically used to simulate rock response to shaped charge penetration do not provide permeability estimates since the rock permeability does not effect the progress of the jet. Hydrocodes developed to simulate these events typically only consider rock properties which directly relate to rock strength and mechanical response (e.g.: porosity). Over the time scale of a shaped-charge perforation, it is assumed that any fluid within the rock has no time to move between pores, hence permeability is assumed irrelevant. Furthermore, jet penetration typically ceases after a few hundreds of microseconds and the post-shot surge period, known to be crucial in determining the final permeability of the perforation, occurs over time scales measuring seconds.

While permeability does not directly impact the mechanical response of the rock, clearly the permeability is expected to change in response to pore collapse, bulking, microfracturing, and fines migration. Many authors have sought to relate final permeability to the stress history of a host rock. Papamichos et al. ${ }^{1}$ used poroelasticity to predict the stresses due to a shapedcharge jet. These results were combined with estimates of grain crushing and a simple permeability rule to estimate the extent of the reduced permeability zone. McKee and Hanson ${ }^{2}$ developed an expression for the radial dependence of permeability in rock created by a single charge. Their technique related permeability to estimates of fracturing due to an explosion. These approaches assumed relatively simple configurations in order to obtain a description of the stress induced in the rock. Zhu and Wong ${ }^{3,4}$ investigated the relationship between permeability and deformation using a network model and provided insight into the formation of connected microcracks and their influence upon permeability.

In previous work ${ }^{5}$, we developed a simple yet robust model which has been incorporated into existing, proven hydrocodes. This approach was suitable only for quasistatic evolution of porosity and permeability. In addition, this approach neglected the influence of free fine particles, which reduce permeability by blocking pores and are expected to be removed by underbalance. Dey ${ }^{6}$ suggests the migration of clay particles may reduce permeability by $30 \%$ after cycles in effective mean stress of as little as $30 \mathrm{MPa}$ (while porosity is observed to be entirely reversible). The perforation process is expected to produce and 
mobilize many fine particles which subsequently reduce permeability and flow performance. It may be reasonable to assume that migration of fines does not have a significant influence on the permeability during the shot of the shaped charge. However, subsequent flushing of the perforation and surrounding rock is expected to lead to substantial changes in permeability due to fines migration.

The migration of fines in porous media in general has been studied in detail by previous authors (see Khilar and Fogler ${ }^{7}$ for a review). Halleck ${ }^{8}$ presented a simple model for predicting the cleanup of the reduced permeability zone. However, this model did not include deposition of fines (and thus, could only predict improvements in permeability with underbalance). Imdakm and Sahimi ${ }^{9}$ used a Monte Carlo technique to predict the reduction in permeability of a network of pores. Injected particles migrated according to a random walk and blocked tubes of smaller radii in the network, reducing the network permeability. Their approach did not allow the possibility of fines being re-entrained into the flow. Wennberg et al. ${ }^{10}$ developed a two-dimensional simulator employing a simple model to investigate the general behavior of deposition processes. Their simulations exhibited the formation of clogged bands both parallel and perpendicular to the flow direction, depending upon the system parameters. Gruesbeck and Collins ${ }^{11}$ performed a series of experiments with synthetic systems and proposed a set of equations governing the evolution of fines concentration. Subsequently, these equations have formed a basis for numerical studies. For example, Ochi and Vernoux ${ }^{12}$ developed a two-dimensional network model that utilized evolution equations similar to those devised by Gruesbeck and Collins ${ }^{11}$. Ochi and Vernoux ${ }^{12}$ used the geometric properties of the network to estimate the model parameters (e.g., entrainment rate and deposition rate). However, their approach did not permit re-entrainment of trapped particles. In addition, in practice it can be difficult to translate the macroscopic properties of the formation (porosity, permeability, damage) into network properties (pore radii, bond lengths). In this work we present a method for simulating the influence of fines migration employing a model after Gruesbeck and Collins ${ }^{11}$. The initial permeability field is obtained from a hydrocode using a modified version of the model presented by Morris et al. ${ }^{5}$. Results from a one-dimensional model simulation are in excellent agreement with measured fines and permeability distributions. We also present two-dimensional numerical results which qualitatively reproduce experimentally obtained permeability maps for different values of underbalance. Further comparison with experiment is essential to tune the coupling between the hydrocode and fines migration simulator. Although, the permeability model is most appropriate for high permeability sandstones (such as Berea), the extension to other rock types should be straightforward, given sufficient experimental data.

\section{Review of Understanding of Perforation and Flow Performance}

Halleck ${ }^{8}$ provides a review of experimental and modeling investigations of the influence of perforations upon flow performance. Halleck ${ }^{8}$ observed that most of the surge cleanup occurs in less than 1 second and suggested that surge flow volume is not an important factor, provided sufficient underbalance is used. Furthermore, Halleck ${ }^{8}$ claimed that most of the cleanup would occur during the initial, high-rate transient flow. In this work we assume that the cleanup processes involves an initial removal of low permeability debris from the tunnel, followed by fines migration. For simplicity we have assumed that fluid flow is Darcian throughout the fines migration stage. Halleck ${ }^{8}$ also observed that permeability damage extends beyond the visibly "crushed zone". He interpreted this as evidence that permeability reduction is more a function of fines migration than of grain breakage itself. In this work we interpret the permeabilities predicted by the hydrocode to be permeabilities of the rock in the absence of fines. Fines are introduced into the simulation as a function of history dependent variables.

Halleck et al. ${ }^{13}$ found that 3000 psi effective overburden stress can be sufficient to reduce penetration by $50 \%$ in Berea Sandstone (although $20 \%$ is more typical). King et al. ${ }^{14}$ studied the effect of post-perforation acidizing on well productivity. They proposed that acidizing leads to increased well productivity for those cases where the underbalance was insufficient. They observed that higher underbalance pressures were needed for lower permeability rocks.

Core-flow efficiency (CFE) provides a standard measure of the perforation flow performance. The CFE is the ratio of measured post-shot flow rate to an ideal rate based upon pre-shot permeability. Core-flow efficiency only provides a bulk description of the net effect of the perforator. For simplicity, many authors assume that the damaged zone is of constant thickness (typically about 0.4 inches) and constant, reduced permeability. In this work we seek a detailed map of the permeability field surrounding the perforation. Several authors have directly measured the permeability field, using a variety of techniques. Rochon et al. ${ }^{15}$ measured the radial distribution of permeability in a perforated core using pressure transient analysis. They found that the permeability fields had a more complex structure than often assumed, with a zone of high permeability near the perforation wall and a minimum several millimeters into the rock. Unfortunately, this approach involves changing the stress conditions of the rock before permeability can be measured. More recently, Karacan and Halleck ${ }^{16}$ used X-ray CT to provide a direct determination of flow velocity in samples while maintaining effective stress conditions. Their results (for 350 psi underbalance) show a gradual reduction in permeability approaching the perforation (see Figure 4a). In contrast with Rochon ${ }^{15}$, Karacan and Halleck ${ }^{16}$ do not observe a region of high permeability near the tunnel wall.

Several other studies have investigated the influence of the perforation upon the rock microstructure. Asadi and Preston ${ }^{17}$ 
used SEM and image analysis to map the damaged zone. They deduced permeabilities using an empirical model calibrated to the undamaged rock sample.

Particle size analysis can provide a direct measure of the distribution of fines and larger particles within a post-shot sample. Halleck ${ }^{18}$ investigated the distribution of fines (particles of diameter 10 micron or less) under balanced conditions and with underbalance in Berea Sandstone. These results indicate that the shot breaks mineral grains near the tunnel, producing a large number of fine particles. For the balanced shot, the fines concentration generally increased towards the tunnel wall, peaking at the wall itself. The underbalanced test results indicated that fines had been removed from the region surrounding the tunnel. However, between 0.5 and 1 " from the centerline the fines concentration was observed to be higher than that of the balanced shot. This suggests that fines migrate during the transient surge phase induced by underbalance.

\section{POROSITY MODEL FOR DYNAMIC CON- DITIONS}

Morris et al. ${ }^{5}$ presented a model for predicting the evolution of the incipient porosity (termed "fluid porosity" in this work to distinguish it from the bulking porosity) and permeability of Berea sandstone undergoing quasistatic deformation. Under quasistatic conditions the fluid is free to equilibrate and the pore pressure is imposed by the surrounding fluid. For dynamic experiments, we assume the fluid does not have time to flow in response to porosity changes. The fluid is confined within individual pores and local fluid pressure responds to changes in pore volume.

In this work, we extend the approach taken by Morris et al. ${ }^{5}$ to accommodate dynamic conditions. We model Berea sandstone as an elastic-plastic material using the method described in detail by Lomov et al. ${ }^{19}$ and Rubin et al. ${ }^{20}$. Morris et al. ${ }^{5}$ assumed that the quasistatic fluid porosity is a function of effective mean stress alone, in the absence of damage:

$$
\phi_{\mathrm{f}}^{0}= \begin{cases}\Phi_{\mathrm{f}}-\sigma_{\mathrm{eff}}\left(\Phi_{\mathrm{f}}-\left(\Phi_{1}+C P_{1}\right)\right) / P_{1} & \text { for } \sigma_{\mathrm{eff}}<P_{1}, \\ \Phi_{1}+C \sigma_{\mathrm{eff}} & \text { otherwise. }\end{cases}
$$

where $\sigma_{\text {eff }}$ is the effective mean stress,

$$
\sigma_{\text {eff }}=\left(\sigma_{1}+\sigma_{2}+\sigma_{3}\right) / 3-P_{p}=P_{m}-P_{p}
$$

and $\phi_{f}^{0}$ is the fluid porosity. The material constants, $\Phi_{\mathrm{f}}, C, P_{1}$, and $\Phi_{1}$ are given in Table 1. Equation (1) reproduces the initial rapid reduction in porosity followed by an extended region of near linear dependence upon effective mean stress before failure observed by Zhu and Wong ${ }^{21}$.

Morris et al. ${ }^{5}$ modeled the influence of damage using a correction to (1):

$$
\phi_{f}^{\mathrm{S}}=\frac{\phi_{f}^{0}\left(\sigma_{\mathrm{eff}}\right)}{1.0+\left(A_{\mathrm{i}}-A_{\mathrm{i} 0}\right)}
$$

where $A_{\mathrm{i}}$ is a damage variable with initial value $A_{\mathrm{i} 0}$. The damage variable is evolved according to

$$
\begin{aligned}
\dot{A}_{\mathrm{i}}= & c_{1} \dot{\varepsilon}_{p} \min \left(\sigma_{\mathrm{eff}}, P_{\mathrm{s}}^{*}\right) \\
& +c_{2} H\left(\sigma_{\mathrm{eff}}-P_{\mathrm{h} 1}\right) H\left(P_{\mathrm{h} 2}-\sigma_{\mathrm{eff}}\right)\langle-\dot{v}\rangle
\end{aligned}
$$

where $c_{1}$ and $c_{2}$ are constants, $\varepsilon_{p}$ is the plastic strain, and $\dot{v}$ is the trace of the velocity tensor (positive indicates expansion). $H()$ is the Heaviside function and $\langle x\rangle=x H(x)$. The first source term increases damage in response to plastic strain. The second term causes damage in response to reductions in volume at high hydrostatic loads and $p_{1 \mathrm{~h}}$ and $p_{2 \mathrm{~h}}$ are the lower and upper bounds on the effective mean stress for which this damage term is active. The parameters in Table 1 were found to give good agreement with experiment.

In this work, we extend this approach to dynamic problems. We use (3) during initial loading, however, the confined fluid is expected to force the voids back to their original volume as the effective mean stress returns to zero. The volume occupied by the fluid as the effective mean stress is reduced $\left(\phi_{f}^{R}\right)$ will be a combination of pore volume which would have opened up under static (drained) conditions $\left(\phi_{\mathrm{f}}^{\mathrm{S}}\right)$ and pore volume which has been forced open by the expanding fluid $\left(\phi_{\mathrm{f}}^{\mathrm{D}}\right)$ :

$$
\phi_{\mathrm{f}}^{\mathrm{R}}=\phi_{\mathrm{f}}^{\mathrm{S}}+\phi_{\mathrm{f}}^{\mathrm{D}}
$$

We assume that the porosity occupied by the fluid under dynamic conditions follows a simple linear form for the return path:

$$
\phi_{\mathrm{f}}^{\mathrm{R}}=\Phi_{\mathrm{f}}-\frac{\sigma_{\mathrm{eff}}}{\sigma_{\mathrm{eff}}^{\max }}\left(\Phi_{\mathrm{f}}-\phi_{\mathrm{f}}^{\mathrm{S}}\left(\sigma_{\mathrm{eff}}^{\max }, A_{\mathrm{i}}\right)\right)
$$

where $\sigma_{\text {eff }}^{\max }$ is the maximum effective stress over the history of the material element. The form of (6) ensures continuity between the fluid porosity during loading and unloading and causes the fluid porosity to return to the reference value when the effective mean stress is zero. The fluid porosity is then given by:

$$
\phi_{\mathrm{f}}= \begin{cases}\phi_{\mathrm{f}}^{\mathrm{S}}, & \text { for } \sigma_{\mathrm{eff}}>\sigma_{\mathrm{eff}}^{\max } \\ \phi_{\mathrm{f}}^{\mathrm{R}}, & \text { for } \sigma_{\mathrm{eff}} \leq \sigma_{\mathrm{eff}}^{\max }\end{cases}
$$

For the dynamic case, pore pressure is not prescribed externally and we introduce an extra equation to close the system and solve for the pore pressure:

$$
P_{p}=K_{\mathrm{f}}\left\langle\frac{S \Phi_{\mathrm{f}}}{\phi_{\mathrm{f}} J}-1\right\rangle
$$

where $K_{\mathrm{f}}$ is the fluid bulk modulus, $J$ is the ratio of current and reference specific volumes of the mixture, and $S$ is a saturation parameter (assumed constant during dynamic experiments). Equation (8) was derived assuming that the pore fluid is confined and obeys a linear equation of state. Eq. 8 refers to 
the fluid porosity, so $P_{p}$ must be eliminated from (8) and (7) to obtain the fluid porosity. Regardless of which portion of Eq. 7 applies, $\phi_{\mathrm{f}}$ is linear in $\sigma_{\text {eff. }}$. The intersection between (8) and a straight line:

$$
\phi_{\mathrm{f}}=D \sigma_{\mathrm{eff}}+E
$$

is given by:

$$
\phi_{\mathrm{f}}=\left(\phi_{1}+\sqrt{\phi_{1}^{2}-4 D K_{f} S \Phi_{\mathrm{f}} / J}\right) / 2
$$

where

$$
\phi_{1}=E+D\left(P_{m}+K_{f}\right)
$$

The effective mean stress is then calculated by backsubstitution into (7)

\section{ESTIMATION OF PERMEABILITY}

As a first approximation, Morris et al. ${ }^{5}$ assumed that although the bulking porosity may be connected (and therefore saturated in quasi-static experiments) it does not make a substantial contribution to flow. This is consistent with the bulking porosity having poor connectivity or higher surface area to volume ratio. Using this approximation, the experimentally measured porosity is the sum of the surviving fluid porosity and induced bulking porosity, however, only the fluid porosity contributes to flow. Morris et al. ${ }^{5}$ obtained good agreement with with experimentally measured permeabilities by using:

$$
\begin{aligned}
\kappa=\exp & \left(-7.84+65.7 \phi_{\mathrm{f}}^{\mathrm{S}}\left(\sigma_{\mathrm{eff}}, A_{\mathrm{i}}\right)\right. \\
& \left.-13.0 \min \left(A_{\mathrm{i}}-A_{\mathrm{i} 0}, 0.11\right)\right)
\end{aligned}
$$

We assume that the permeability due to the bulking porosity and $\phi_{\mathrm{f}}^{\mathrm{D}}$ can be neglected in comparison with the permeability due to $\phi_{\mathrm{f}}^{\mathrm{S}}$. This approximation may not be appropriate for low porosity/permeability rocks where the permeability of the bulking porosity may exceed the initial permeability. Future work will concentrate on developing a more comprehensive approach to estimating permeability by linking damage to permeability directly through the concept of interstitial area.

\section{MODEL FOR ENTRAINMENT AND DEPO- SITION}

We employ a model after Gruesbeck and Collins ${ }^{11}$. Their approach assumes that the porous medium may be modeled locally by parallel-pathways (see Fig. 1). In a given representative elemental volume (REV) of the pore space it is assumed that the fluid pathway has two continuing, parallel branches: one of small size in which fines can form plugs, and the other, of larger pore size, in which only surface non-plugging deposits occur. Fines trapped in the plugging pores cannot be released, while fines in the non-plugging pores can be re-entrained by the fluid. The ratio of the fines size to the pore size determines what fractions of flow pathways are plugging or non-plugging.
Within each REV we divide the fines into three concentrations:

C concentration of free fines,

carried in suspension by the fluid

$\sigma_{\mathrm{np}} \quad$ concentration of fines on walls of non-plugging pores

$\sigma_{\mathrm{p}} \quad$ concentration of fines on walls of plugging pores concentrations are expressed in terms of volume of solid per unit volume of fluid (m3/m3). In particular, $\sigma_{\mathrm{np}}$ and $\sigma_{\mathrm{p}}$ are volumes of solid per unit volume of fluid in non-plugging and plugging pores respectively. Within each REV it is assumed the pore volume can be divided into a fraction $f$ which consists of pluggable pathways and a fraction $1-f$ which is non-pluggable. The value of $f$ will depend upon the local distribution of pore diameters and the particle size distributions of fines. In the applications considered by Gruesbeck and Collins ${ }^{11} f$ was constant throughout space, however, for other applications, $f$ can vary from point to point to model variations in pore or particle distributions.

Gruesbeck and Collins ${ }^{11}$ performed a series of experiments with synthetic systems and proposed a set of equations governing the evolution of $C, \sigma_{\mathrm{np}}$, and $\sigma_{\mathrm{p}}$. If we assume the fines occupy a relatively small fraction of the available pore volume, the mass balance of fines can be stated:

$$
\phi \frac{\partial C}{\partial t}=-u \frac{\partial C}{\partial x}-\phi \frac{\partial \sigma}{\partial t}
$$

Here $\phi$ is the porosity, $u$ is the volume flux density $(q / A)$ and $\sigma$ is total concentration of deposited fines:

$$
\begin{gathered}
\sigma=f \sigma_{\mathrm{p}}+(1-f) \sigma_{\mathrm{np}} \\
u=f u_{\mathrm{p}}+(1-f) u_{\mathrm{np}}
\end{gathered}
$$

Here $u_{\mathrm{p}}$ and $u_{\mathrm{np}}$ are the volume flux densities in the plugging and non-plugging pores respectively.

In the non-plugging pathways, entrainment and deposition can occur, and Gruesbeck and Collins ${ }^{11}$ proposed the following form to fit their experimental results:

$$
\frac{\partial \sigma_{\mathrm{np}}}{\partial t}=-\alpha\left\langle u_{\mathrm{np}}-u_{\mathrm{c}}\right\rangle \sigma_{\mathrm{np}}+\beta C
$$

Here, $u_{\mathrm{c}}$, denotes the critical volume flux density required to entrain particles and $\alpha$ and $\beta$ are constants, and

$$
\langle x\rangle= \begin{cases}0, & \text { if } x<0, \\ x, & \text { otherwise. }\end{cases}
$$

The plugging pathways only permit particle deposition:

$$
\frac{\partial \sigma_{\mathrm{p}}}{\partial t}=\left(\delta+\rho \sigma_{\mathrm{p}}\right) u_{\mathrm{p}} C
$$

Here $\delta$ and $\rho$ are constants. Gruesbeck and Collins ${ }^{11}$ argued this form is appropriate since plugging deposition cannot occur for zero $u_{\mathrm{p}}$.

Gruesbeck and Collins ${ }^{11}$ used Darcy's law to describe flow diversion phenomena in terms of the permeabilities of the plugging $\left(K_{\mathrm{p}}\right)$ and non-plugging $\left(K_{\mathrm{np}}\right)$ paths. The permeabilities were assumed to be functions of the deposited fines fraction. 


\section{APPLICATION OF THEORY TO PER- MEABILITY DAMAGE DUE TO SHAPED CHARGE PERFORATION}

In this work we consider a cylinder of rock, discretized into a regular cylindrical co-ordinate system. Within each cell we apply the equations for evolution of $C, \sigma_{\mathrm{np}}$, and $\sigma_{\mathrm{p}}$ and calculate fluxes of particles between cells using fluid fluxes based upon Darcy's law. The pressure field at each time step is obtained using a Poisson solver. To demonstrate the suitability of the model of Gruesbeck and Collins ${ }^{11}$, we first consider a model one-dimensional problem which captures the key features of the experimentally observed results.

Permeability measurements obtained by Karacan and Halleck $^{22}$ (see Figure 4a) for 750 psi underbalance in Berea Sandstone exhibit a reduced permeability zone at a radius of $2 \mathrm{~cm}$ from the tunnel axis. Halleck ${ }^{18}$ investigated the distribution of fines (particles of diameter 10 micron or less) under balanced conditions and with underbalance for Berea Sandstone. For the balanced shot, the fines concentration generally increased towards the tunnel wall, peaking at the wall itself. The 1500 psi underbalance test results indicated that fines had been removed from the region surrounding the tunnel. However, between 0.5 and 1 " from the center the fines concentration was observed to be higher than that of the balanced shot. This suggests that fines migrate during the transient surge phase induced by underbalance. These results also suggest a model in which there are four zones where different fines erosion and deposition processes are at work for sufficient underbalance in Berea Sandstone (see Figure 2). The balanced fines concentration peaks in region I, closest to the tunnel wall. Underbalance, however, removes most of the fines from region I. In region II, permeability reduction is observed for sufficient underbalance (see Figure 4a), suggesting fines have migrated here and have been deposited. Region III exhibits a slight reduction in fines concentration with underbalance and is the probable source of the fines deposited into region II. Region IV shows relatively little change in fines concentration between balanced and underbalanced conditions.

We expect the pore volumes to be most restricted in region I, since this corresponds to the most damaged rock. The underbalanced results suggest that even with these small pores, the fines can still be flushed out. This implies that there are no plugging pores in region I (since these could be expected to permanently capture a fraction of the fines). In this work we assume that the rock contains non-plugging pores throughout and that fines may be re-entrained at any location, given sufficient flow velocity.

If we assume the flow during the transient surge resulting from underbalance is radially symmetric (no axial flow) then the local flow velocity is:

$$
u=\frac{Q}{2 \pi r}
$$

where $Q$ is the rate of flux into the tunnel from the reservoir.
Clearly region I will have the highest flow velocity, possibly greatly exceeding $u_{\mathrm{c}}$, and consequently extensive fines erosion occurs. Region II will have a lower flow velocity, possibly below $u_{\mathrm{c}}$, leading to a net accumulation of fines. However, we observe that fines are removed from region III, where the flow velocity is even lower. This suggests that $u_{\mathrm{c}}$ may have a lower value in region III than in region I or II. In this work we assume that $\alpha$ and $\beta$ are uniform throughout the flow domain and that the critical flow velocity, $u_{\mathrm{c}}$, varies depending upon the damage sustained by the rock. Figure 3 demonstrates how variations of $u_{\mathrm{c}}$ with radius can lead to alternating zones of fines erosion and deposition. In Figure 3 we have taken the simplest approach with $u_{\mathrm{c}}$ having a constant initial, undamaged value and assume a higher, constant value in the damaged zone.

We have exercised this simple model with our fines migration simulator. Our simulator is fully two-dimensional, but for this simple problem we constructed a one-dimensional problem by considering a cylinder of rock of radius $4.5 \mathrm{~cm}$, length $1 \mathrm{~cm}$, discretized into square cells of dimension $0.75 \mathrm{~mm}$ with a tunnel of radius $0.75 \mathrm{~cm}$ along the axis. We assume that the rock contains non-plugging pores only:

$$
f=0
$$

For the model problem we assume a simple linear dependence of the permeability in the absence of fines:

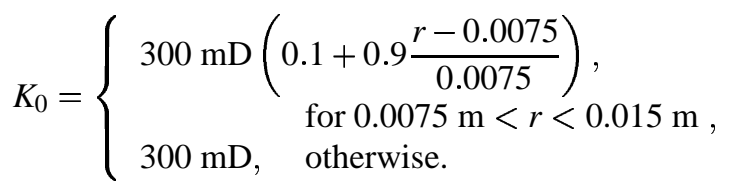

There was no variation in permeability in the axial direction, thus the resulting flow is radially symmetric. We use the following values for the entrainment and capture rate constants:

$$
\begin{aligned}
& \alpha=1700 \mathrm{~m}^{-1} \\
& \beta=11 \mathrm{~s}^{-1}
\end{aligned}
$$

We also assume a simple linear dependence of permeability upon local concentration of trapped fines which approximately maps the measured fines concentrations ${ }^{18}$ to the measured permeabilities (Figure 4a)

$$
K=K_{0}\left(1-3 \sigma_{\mathrm{np}}\right)
$$

The critical flow rate, $u_{\mathrm{c}}$, is assumed piecewise constant, with a larger value in a damaged zone within $2.5 \mathrm{~cm}$ :

$$
u_{\mathrm{c}}= \begin{cases}0.0375 \mathrm{~m} / \mathrm{s}, & \text { for } r<0.025 \mathrm{~m}, \\ 0.0113 \mathrm{~m} / \mathrm{s}, & \text { otherwise }\end{cases}
$$

The volume of free fines per fluid volume was initially set to:

$$
C=\frac{1}{3}\left[(0.005 / r)^{2}+0.1\right]
$$


The initial trapped fines concentration was zero. Pressure boundary conditions representing 750 psi underbalance were applied to the tunnel and outer surface of the problem, with no-flow boundaries at either end. The results obtained by the fines migration simulator after 1 second of flushing are compared with experiment in Figure 4. The results are generally in good agreement, with the simulation exhibiting the observed alternating zones of fines erosion and deposition. The simulations of $750 \mathrm{psi}$ underbalance show accumulation of fines between about $1.5 \mathrm{~cm}$ and $2.5 \mathrm{~cm}$ with removal of fines elsewhere. The shape of the fines profile between $1.5 \mathrm{~cm}$ and $2.5 \mathrm{~cm}$ is determined by the relative value of $\alpha$ and $\beta$. A larger value of $\beta$ results in more fines accumulating near $2.5 \mathrm{~cm}$. In the following section, we apply this same approach to the clean-up process in a fully two-dimensional permeability field obtained from a separate hydrocode simulation of the penetrator.

\section{Mapping the Hydrocode Results to the Fines Simulator}

We seek to map the results from the end of the hydrocode simulation of perforation into suitable values for fines concentration, permeability in the absence of fines, and $u_{\mathrm{c}}$. The initial conditions obtained must be consistent with the available experimental data and yet be simple to implement with a minimum number of assumptions.

Figure 5 shows a permeability map as a function of distance from the tunnel wall and distance from the entrance, for Berea Sandstone perforated with 350 psi underbalance, obtained by Karacan and Halleck ${ }^{22}$. These results show reduced permeability near the tunnel with particularly low permeabilities near the entrance and towards the other end of the tunnel. Figure 6 and 7 show the permeability field predicted by the hydrocode simulation with and without fines, respectively, for balanced conditions. Although exhibiting significant variability, the hydrocode permeability predictions also show reduced permeability near the tunnel wall, with permeability reduction largest near the opening. The axial variation in permeability predicted by simulation is in contrast with the interpretation of Karacan and Halleck $^{22}$. They attribute the axial variation in permeability to variations in the pre-shot permeability of the rock because the outermost permeability measurements approach a constant near the opening and at the other end of the tunnel (indicating the permeability is independent of radius beyond $1.5 \mathrm{~cm}$ at these locations). However, the outermost permeabilities measured between $5 \mathrm{~cm}$ to $10 \mathrm{~cm}$ from the tunnel entrance differ, casting some doubt on this interpretation. Nevertheless, despite these qualitative differences between hydrocode simulation and experiment it is possible to achieve a global fit of post-fines migration permeability to experiment. By varying $\alpha, \beta$, and $u_{\mathrm{c}}$ throughout the problem, permeability can be enhanced or decreased in order to reduce the differences between measurement and simulation. However, given the limited experimental data available to match against, it is unclear that such a global fit would be informative. For example, given one permeability map it is unclear whether it is the hydrocode parameters or the fines migration parameters which should be modified to achieve a better fit. In this work, therefore, we attempted to match the observed clean-up at certain locations along the perforation, assuming that $\alpha$ and $\beta$ were constant throughout, and related $u_{\mathrm{c}}$ directly to hydrocode history dependent variables. Once more measured permeability maps are available (both for a wider range of underbalances and for multiple cores at each level of underbalance) it will be possible to determine what parameters are needed within the hydrocode and the functional forms for $\alpha, \beta$, and $u_{\mathrm{c}}$ in terms of hydrocode history dependent variables.

We assume that the permeability obtained from the hydrocode (12) represents the permeability of the rock in the absence of fines. The experimental data of Zhu and Wong ${ }^{21}$ (upon which our hydrocode permeability model is based) provide no insight into the role of fines migration. We assume that the shock loading accompanying perforation releases more fines and that it is appropriate to consider the hydrocode permeabilities as an upper limit in the absence of fines.

Our fines migration simulator cannot simulate the observed removal of debris from the tunnel, so we need to make some assumptions regarding how much material is removed. Furthermore, Halleck ${ }^{8}$ claimed that most of the cleanup would occur during the initial, high-rate transient flow, at which point the pressure gradient will be highest across low permeability regions. We assume that all material with permeability lower than $6 \mathrm{mD}$ is removed. The removal of this material is simulated by replacing it with material with a permeability of $10000 \mathrm{mD}$.

At the start of the fines migration simulation it is assumed that all available fines are shaken loose into suspension. The following was found to give good agreement with the experimentally measured fines fraction ${ }^{18}$ for balanced conditions as a function of radius:

$$
\begin{aligned}
C & =\frac{1}{3} \sqrt{\varepsilon_{\mathrm{p}} / 0.3} \\
\sigma_{\mathrm{p}} & =0 \\
\sigma_{\mathrm{np}} & =0
\end{aligned}
$$

Here $\varepsilon_{\mathrm{p}}$ is the local plastic strain in the rock predicted by the hydrocode.

The critical velocity, $u_{\mathrm{c}}$, is a key parameter which determines where fines erosion and deposition will occur. We found that

$$
u_{\mathrm{c}}=0.025 \min \left(220 \varepsilon_{\mathrm{p}}, 1.0\right)^{2}
$$

worked well in reproducing the capture of fines at a radius of about $2 \mathrm{~cm}$.

For simplicity the other model parameters were assumed constant:

$$
\begin{aligned}
& \alpha=1120 \mathrm{~m}^{-1} \\
& \beta=22.5 \mathrm{~s}^{-1}
\end{aligned}
$$

These parameters determine the timescale over which cleanup occurs. The value of these parameters was found to be less cru- 
cial, provided there is sufficient time to flush the fines. This reflects Halleck's ${ }^{8}$ observation that surge flow volume is not an important factor provided sufficient underbalance is used. It may be more appropriate to vary these parameters with position, however insufficient data were available to provide a rationale for a functional form for $\alpha$ and $\beta$.

As with the model problem, we assumed a simple linear dependence of permeability upon local concentration of trapped fines which approximately maps the measured fines concentrations to the measured permeabilities:

$$
K=K_{0}\left(1-3 \sigma_{\mathrm{np}}\right)
$$

This approach was used to simulate the penetration tests performed by Karacan and Halleck ${ }^{22}$. Figure 8 shows a twodimensional map of the permeability enhancement for the 750 psi simulation. The simulation predicts permeability enhancement in the vicinity of the tunnel wall with a reduction in permeability (due to fines accumulation) beyond $6 \mathrm{~cm}$ from the tunnel entrance between about 2 and $3 \mathrm{~cm}$ radius. Karacan and Halleck $^{22}$ do not provide a permeability map for $750 \mathrm{psi}$ underbalance, but provide detailed radial permeability profiles only at $3.4 \mathrm{~cm}$ (750 psi case) and $2.8 \mathrm{~cm}$ (350 psi case) from the tunnel entrance. Figures 9 and 10 compare experiment and simulated results as a function of distance from the tunnel wall to remove the effect of variations in tunnel diameter. The radial profiles from Karacan and Halleck ${ }^{22}$ were made to be a function of distance from the tunnel wall using tunnel diameters of $1.3 \mathrm{~cm}(750 \mathrm{psi})$ and $1.2 \mathrm{~cm}(350 \mathrm{psi})$. The best fit to the observed clean-up and fines migration was at a distance of $9.5 \mathrm{~cm}$ from the entrance (see Figure 9). Closer to the tunnel entrance the hydrocode simulation predicts greater permeability reduction, and consequently the flux density is lower and relatively little fines removal occurs. Toward the tip of the penetration at a distance of $13.2 \mathrm{~cm}$ from the entrance the simulated permeability profile is similar to that observed by Karacan and Halleck ${ }^{22}$ at $3.4 \mathrm{~cm}$ although the simulated permeability is higher close to the wall. In addition, Figure 10 shows that the higher simulated permeability at this distance from the entrance permits removal of fine particles within about $0.25 \mathrm{~cm}$ of the tunnel wall even for 350 psi underbalance.

\section{DISCUSSION}

We have presented an approach for predicting the details of permeability damage and cleanup around perforation tunnels. Results obtained using a model one-dimensional simulation of the clean-up process are in excellent agreement with experiment. We also presented a fully two-dimensional approach involving two steps:

- Calculate damage and permeability in the absence of fines using a hydrocode.

- Estimate cleanup using a fines migration simulator.
The results of the simulations are in qualitative agreement with available experimental results. The predicted permeability and fines distributions are in good agreement with experiment at certain locations along the core. However, the permeability field predicted by the hydrocode exhibits significant variability along the core, with greatly reduced permeability at the entrance and relatively little reduction towards the tip. The permeability maps obtained by Karacan and Halleck ${ }^{22}$ also show similar variation in permeability parallel to the tunnel. Karacan and Halleck ${ }^{22}$ argue that when normalized, this variation is reduced, however, more results for multiple cores are required to confirm this interpretation. Beyond a distance of $7 \mathrm{~cm}$ from the tunnel entrance, the simulations show similar zones of fines erosion and deposition to those observed experimentally. Closer to the tunnel entrance the predicted permeability is lower and less fines migration occurs. Given the limited experimental data available to match against, it is unclear whether it is the hydrocode parameters or the fines migration parameters which should be modified to achieve a better fit. Although $\alpha$ and $\beta$ are expected to vary with damage, in this work we attempted to match the observed clean-up at certain locations along the perforation, assuming that $\alpha$ and $\beta$ were constant throughout, and related $u_{\mathrm{c}}$ directly to the plastic strain predicted by the hydrocode. Once more measured permeability maps are available (both for a wider range of underbalances and for multiple cores at each level of underbalance) it will be possible to determine appropriate parameters within the hydrocode and the fines migration simulator. In particular, a more comprehensive series of measured permeability maps will enable functional forms for $\alpha, \beta$, and $u_{\mathrm{c}}$ in terms of hydrocode history dependent variables (damage, strain, porosity) to be determined.

In this work we considered only the behavior of Berea Sandstone. Berea Sandstone differs from many other sandstones in that is is both highly permeable and has a substantial clay content. Consequently, Berea Sandstone may be more susceptible to the release, migration, and subsequent deposition of fines than most other rocks ${ }^{18}$. Experimentally measured permeability maps for a wider range of rocks are required before the model presented in this work can be used to predict the behavior for other rocks. In this work we have not considered the rate of the cleanup process (governed by $\alpha$ and $\beta$ ). A more comprehensive study, addressing the role of flow volume during the post perforation surge, and employing more measured permeability maps, would provide stricter bounds upon the model parameters. In addition, we have not addressed the processes whereby very low permeability rubble is removed from the tunnel, but have used a cutoff to determine what material is removed. A separate model could be developed (possibly similar to that used by $\mathrm{Halleck}^{8}$ ) to simulate this process.

The permeability obtained from the hydrocode employed a damage variable which is not defined in terms of pore-scale properties. However, we have attempted to relate the damage predicted by the hydrocode to the initial fines concentration and critical volume flux within the core. A more versatile approach 
would employ a damage variable directly associated with the evolution of pore-scale properties, such as the interstitial area. This would be more amenable to physical arguments regarding fines production, permeability, and critical volume flux. It would also be more capable of predicting the response of other rocks or the effect of different pore fluids.

We expect the methods developed in this paper to lead to more efficient cleanup of perforations. For example, once sufficient data are obtained to characterize model parameters, it should be possible to substantially reduce the number of tests required to obtain best results. Computer simulation will help identify the optimum balance conditions and surge rate for a given perforator and operating conditions, and also perhaps allow exploration of new concepts such as whether multiple surges might improve core flow efficiency.

\section{ACKNOWLEDGEMENTS}

This work was performed under the auspices of the U.S. Department of Energy by University of California Lawrence Livermore National Laboratory under contract No. W-7405-Eng48. Funding for this project was provided by DOE/NETL and the overall project manager was James R. Ammer.

\section{References}

1. E. Papamichos, I. Vardoulakis, and H. Ouadfel, "Permeability reduction due to grain crushing around a perforation," Int. J. Rock Mech. Sci. \& Geomech. Abstr., vol. 30, no. 7, pp. 1223-1229, 1993.

2. C. R. McKee and M. E. Hanson, "Explosively created permeability from single charges," Soc. Pet. Eng. J., vol. 15, no. 6, pp. 495-501, 1975.

3. W. Zhu and T.-f. Wong, "Permeability reduction in a dilating rock: Network modeling of damage and tortuosity," Geophys. Res. Lett., vol. 23, no. 22, pp. 3099-3102, 1996.

4. W. Zhu and T.-f. Wong, "Network modeling of the evolution of permeability and dilatancy in compact rock," J. Geophys. Res., vol. 104, no. B2, pp. 2963-2971, 1999.

5. J. P. Morris, I. N. Lomov, and L. A. Glenn, "A simple model for permeability and porosity evolution of berea sandstone," Submitted to J. Geophys. Res., 2001. in review.

6. T. N. Dey, "Permeability and electrical conductivity changes due to hydrostatic stress cycling of Berea and Muddy J sandstone,” J. Geophys. Res., vol. 91, no. B1, pp. 763-766, 1986.

7. K. C. Khilar and H. S. Fogler, Migration of Fines in Porous Media. Kluwer Academic Publishers, 1998.

8. P. M. Halleck, "Advances in understanding perforator penetration and flow porformance," SPE 27981, 1994. presented at the University of Tulsa Centennial Petroleum Engineering Symposium, Tulsa, OK, U.S.A., 29-31, August 1994.
9. A. O. Imdakm and M. Sahimi, "Transport of large particles in flow through porous media," Phys. Rev. A, vol. 36, no. 11, pp. 5304-5309, 1987.

10. K. E. Wennberg, G. G. Batrouni, A. Hansen, and P. Horsrud, "Band formation in deposition of fines in porous media," Trans. Por. Media, vol. 25, pp. 247-273, 1996.

11. C. Gruesbeck and R. E. Collines, "Entrainment and deposition of fine particles in porous media," Soc. Petrol. Eng. J., vol. 22, no. 6, pp. 847-856, 1982.

12. J. Ochi and J.-F. Vernoux, "A two-dimensional network model to simulate permeability decrease under hydrodynamic effect of particle release and capture," Trans. Por. Media, vol. 37, pp. 303-325, 1999.

13. P. M. Halleck, R. J. Saucier, L. A. Behrmann, and T. J. Ahrens, "Reduction of jet perforator penetration in rock under stress," SPE 18245, 1988. presented at the 1988 SPE Annual Technical Conference and Exhibition, Houston, TX, Oct. 2-5.

14. G. E. King, M. D. Bingham, and R. W. Kidder, "Factors affecting perforating charge performance and relationship to port plug condition," SPE Production Engineering, pp. 379387, Sept. 1986.

15. J. Rochon, M. Creusot, D. Feugas, S. Thibeau, and J.-L. Bergerot, "Viscous fluids charactize the crushed zone," SPE 27383, 1994. presented at the International Symposium on Formation Damage, Lafayette, LA, February, 7-10.

16. C. O. Karacan and P. M. Halleck, "Mapping of permeability damage around perforation tunnels," in Proceedings of ETCE/OMAE2000 Joint Conference, Energy for the New Millenium, 2000. February 14-17, New Orleans, LA.

17. M. Asadi and F. W. Preston, "Characterization of the crushed-zone formed during jet perforation by qualitative scanning electron microscopy and quantitative image analysis," SPE 22812, 1991. presented at the SPE Annual Technical Conference and Exhibition, Dallas, TX, October 6-9.

18. P. M. Halleck private communication.

19. I. N. Lomov, M. Hiltl, O. Y. Vorobiev, and L. A. Glenn, "Simulation of the dynamic behavior of Berea sandstone," Tech. Rep. UCRL-JC-136898, Lawrence Livermore National Laboratory, 2000. (submitted to Int. J. Num. Appl. Meth. Geomech.).

20. M. B. Rubin, O. Y. Vorobiev, and L. A. Glenn, "Mechanical and numerical modeling of a porous elastic-viscoplastic material with tensile failure," Int. J. Solids and Structures, vol. 37, pp. 1841-1871, 2000. 
Table 1: Parameters used by Lomov et al. ${ }^{19}$ to fit gas gun experiments combined with permeability model parameters chosen to fit Zhu and Wong ${ }^{21}$ measurements.

\begin{tabular}{|c|c|c|c|}
\hline Properties & Parameter & Notation & Value \\
\hline Porosity- & Reference fluid porosity & $\Phi_{f}$ & 0.214 \\
\hline Permeability & Fluid porosity reduction rate & $C$ & $-0.1030 \mathrm{GPa}^{-1}$ \\
\hline \multirow[t]{7}{*}{ Model } & Critical effective pressure & $P_{1}$ & $0.010 \mathrm{GPa}$ \\
\hline & Fluid porosity intercept & $\Phi_{1}$ & 0.1923 \\
\hline & Plastic strain damage rate & $c_{1}$ & 27.0 \\
\hline & Maximum pressure enhanced strain damage & $p_{s}^{*}$ & $0.2 \mathrm{GPa}$ \\
\hline & Hydrostatic pressure damage rate & $c_{2}$ & 27.0 \\
\hline & Minimum pressure for hydrostatic damage & $p_{\mathrm{h} 1}$ & $0.3 \mathrm{GPa}$ \\
\hline & Maximum pressure for hydrostatic damage & $p_{\mathrm{h} 2}$ & $0.4 \mathrm{GPa}$ \\
\hline \multirow{6}{*}{$\begin{array}{l}\text { Equation of } \\
\text { State }\end{array}$} & Reference density & $\rho_{0}$ & $2.32 \mathrm{~g} / \mathrm{cm}^{3}$ \\
\hline & Initial sound speed & $C_{0}$ & $2.00 \mathrm{~km} / \mathrm{s}$ \\
\hline & Hugoniot slopes & $s_{1}$ & 2.76 \\
\hline & & $s_{2}$ & -1.986 \\
\hline & & $s_{3}$ & -1.987 \\
\hline & Grüneisen coefficient & $\Gamma$ & 0.5 \\
\hline \multirow[t]{3}{*}{ Elastic } & Initial shear modulus & $G_{0}$ & $1.625 \mathrm{GPa}$ \\
\hline & Shear modulus slope & $k_{1}$ & $4.540 \mathrm{MPa}^{-1}$ \\
\hline & Shear modulus coefficient & $k_{2}$ & $0.3971 \mathrm{MPa}^{-1}$ \\
\hline \multirow{5}{*}{$\begin{array}{l}\text { Plastic: } \\
\text { Mohr- } \\
\text { Coulomb } \\
\text { friction }\end{array}$} & Initial yield & $Y_{0}$ & $11 \mathrm{MPa}$ \\
\hline & Pressure hardening slope & $k_{3}$ & $121 \mathrm{GPa}^{-1}$ \\
\hline & Pressure hardening coefficient & $k_{4}$ & $0.9957 \mathrm{GPa}^{-1}$ \\
\hline & Strain hardening threshold & $Y_{1}$ & $230 \mathrm{MPa}$ \\
\hline & Strain hardening coefficient & $\mathrm{K}$ & $20 \mathrm{GPa}$ \\
\hline \multirow{3}{*}{$\begin{array}{l}\text { Plastic: Strength } \\
\text { of undamaged } \\
\text { material }\end{array}$} & Strength coefficient & $A$ & $0.8956 \mathrm{GPa}$ \\
\hline & Critical plastic strain & $B$ & 158.6 \\
\hline & Pressure slope & $C$ & $201.2 \mathrm{GPa}^{-1}$ \\
\hline $\begin{array}{l}\text { Löde angle } \\
\text { parameters }\end{array}$ & $\begin{array}{l}\text { Dilation pressure } \\
\text { Mohr-Coulomb-Mises transition }\end{array}$ & $\begin{array}{l}p_{d} \\
\mathrm{Q}\end{array}$ & $\begin{array}{l}0.01 \mathrm{MPa} \\
0.0291\end{array}$ \\
\hline \multirow[t]{2}{*}{ Bulking } & Coefficient & $m_{d}$ & 1.0 \\
\hline & Maximum porosity & $\phi_{b m}$ & 0.25 \\
\hline
\end{tabular}

21. W. Zhu and T.-f. Wong, "The transition from brittle faulting to cataclastic flow: Permeability evolution," J. Geophys. Res., vol. 102, no. B2, pp. 3027-3041, 1997.
22. C. O. Karacan and P. M. Halleck, "Mapping of permeability damage around perforation tunnels," in Proceedings of ETCE/OMAE2000, Joint Conference, Energy for the New Millenium, 2000. February 14-17, 2000, New Orleans, LA. 


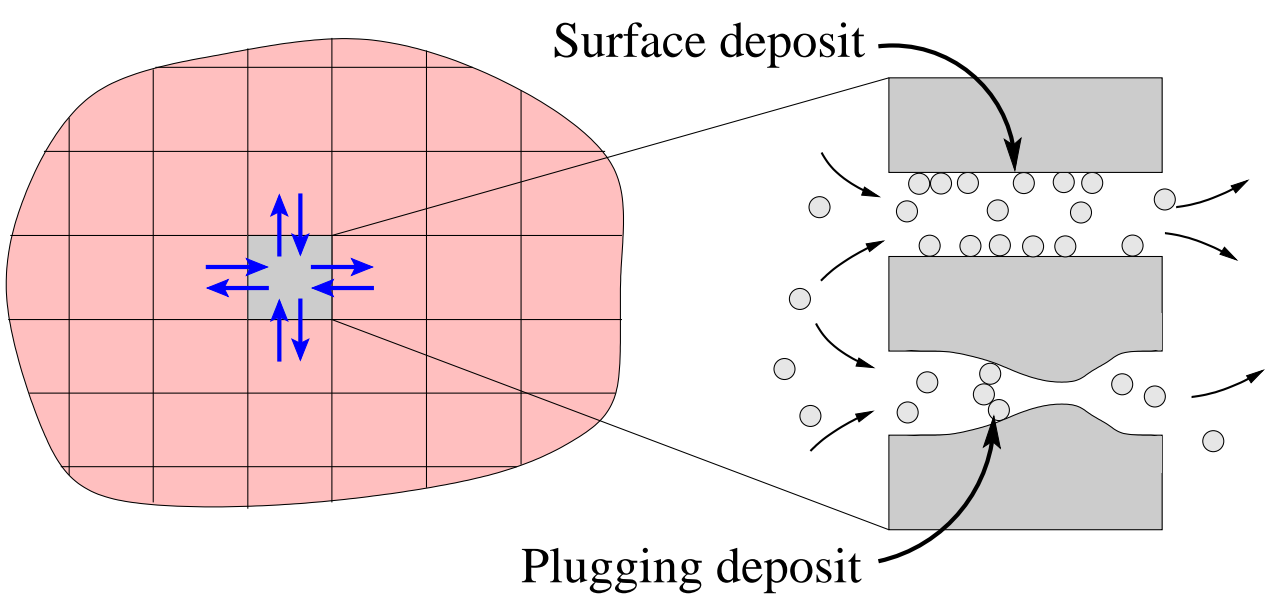

Figure 1: Parallel pathway model of fines entrainment and deposition.

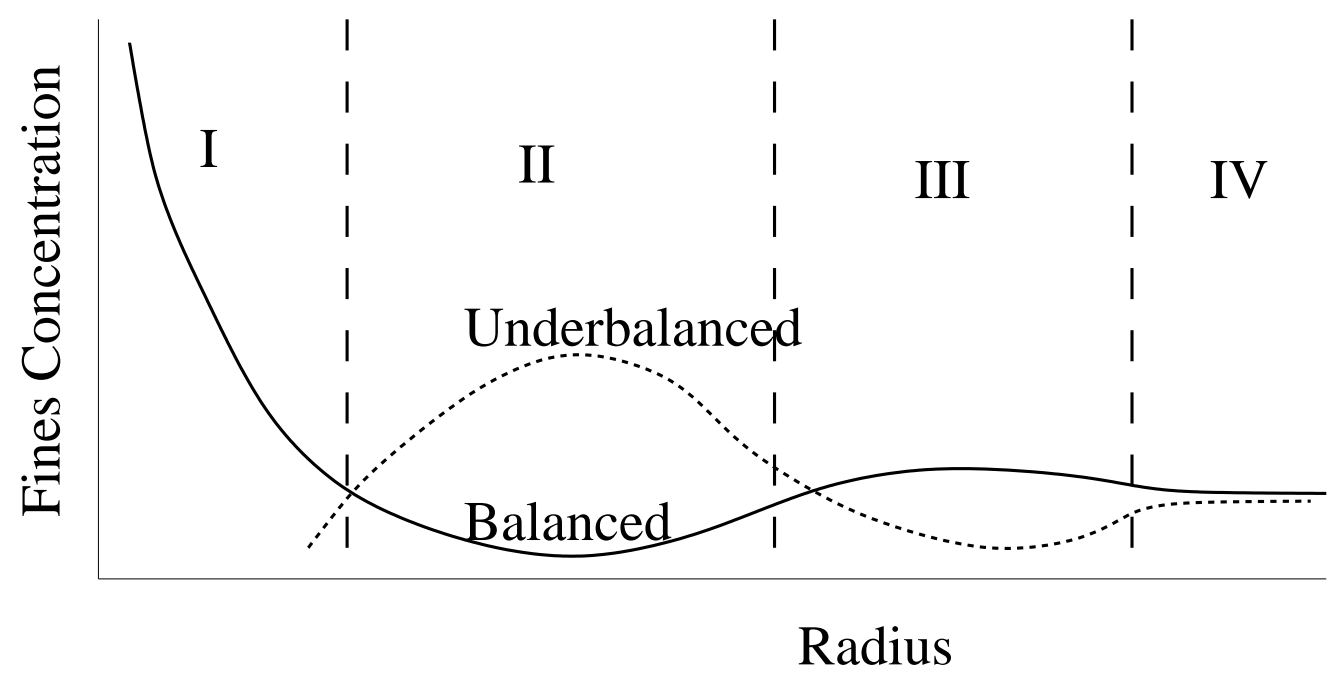

Figure 2: Different zones of fines erosion and deposition. 


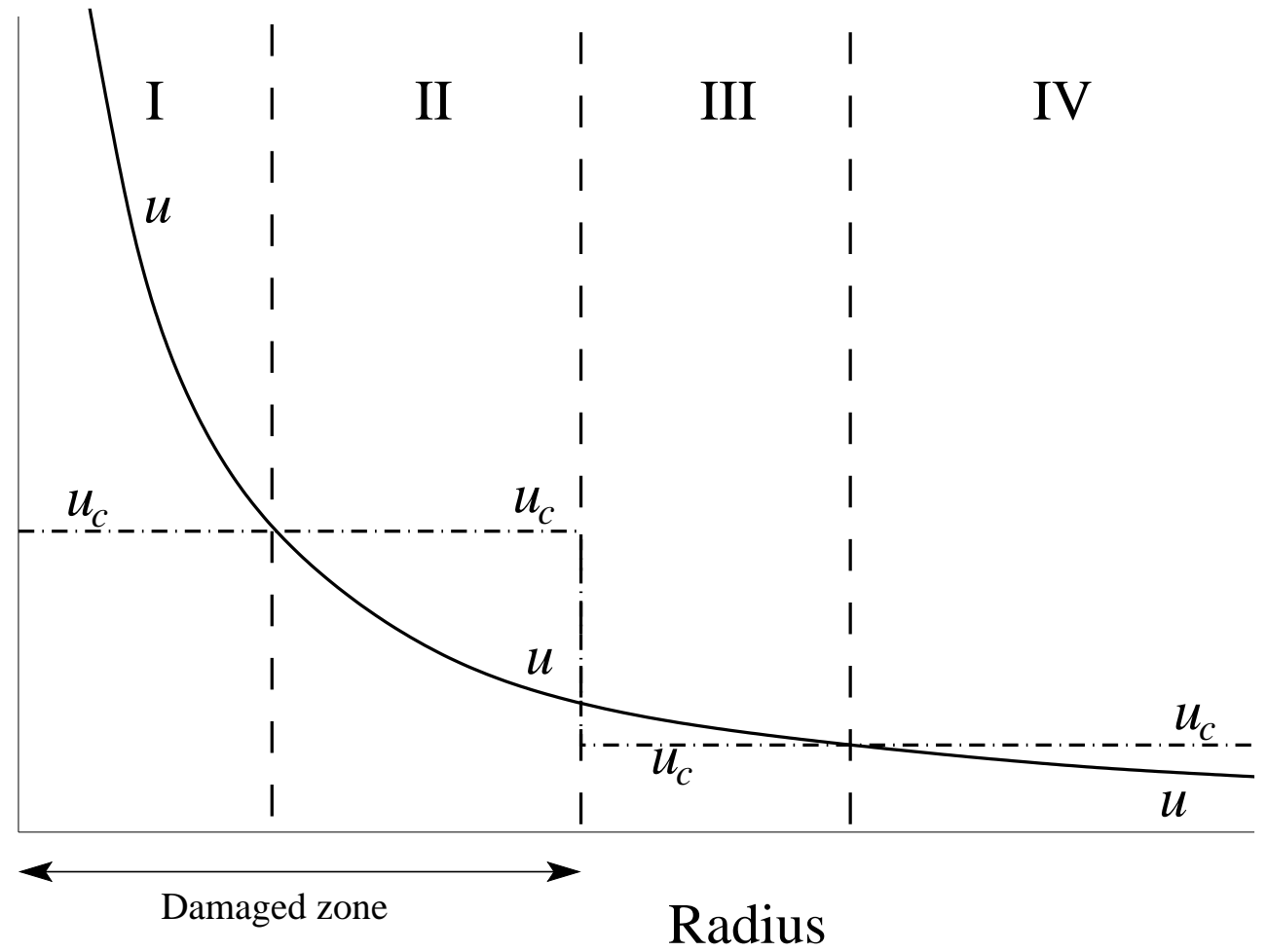

Figure 3: Radial variations in $u_{\mathrm{c}}$ can lead to alternating regions of erosion and deposition. 

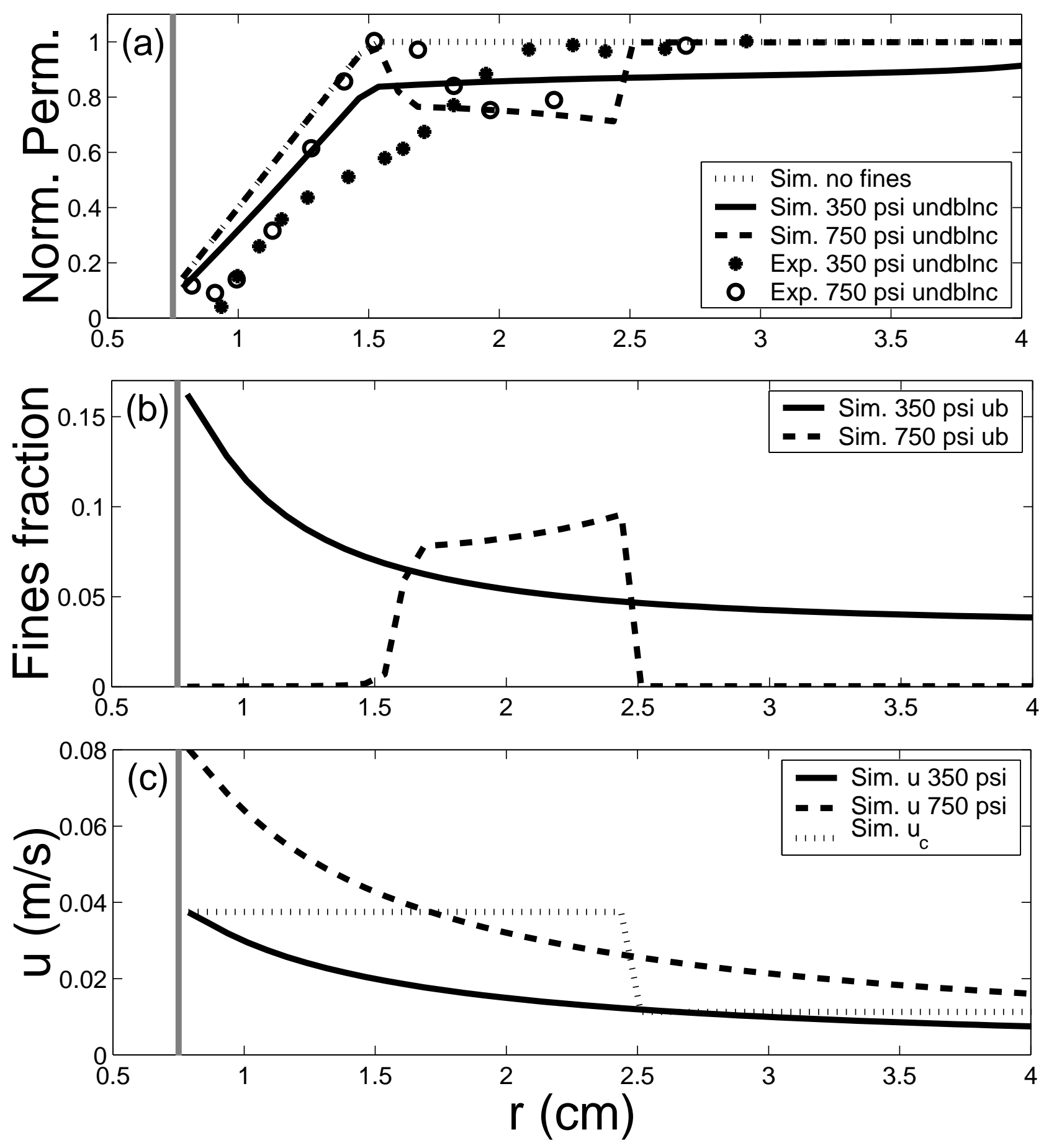

Figure 4: A comparison of experimentally measured permeability evolution with results from the fines migration simulator for a simple, one-dimensional model problem. The vertical gray line indicates the position of the tunnel wall.(a) Normalized permeability measured by Karacan and Halleck ${ }^{22}$ compared with simulation. (b) Simulated fines fraction. (c) Calculated volume flux density $(u)$ as a function of radius, compared with the critical flux density $\left(u_{\mathrm{c}}\right)$. 


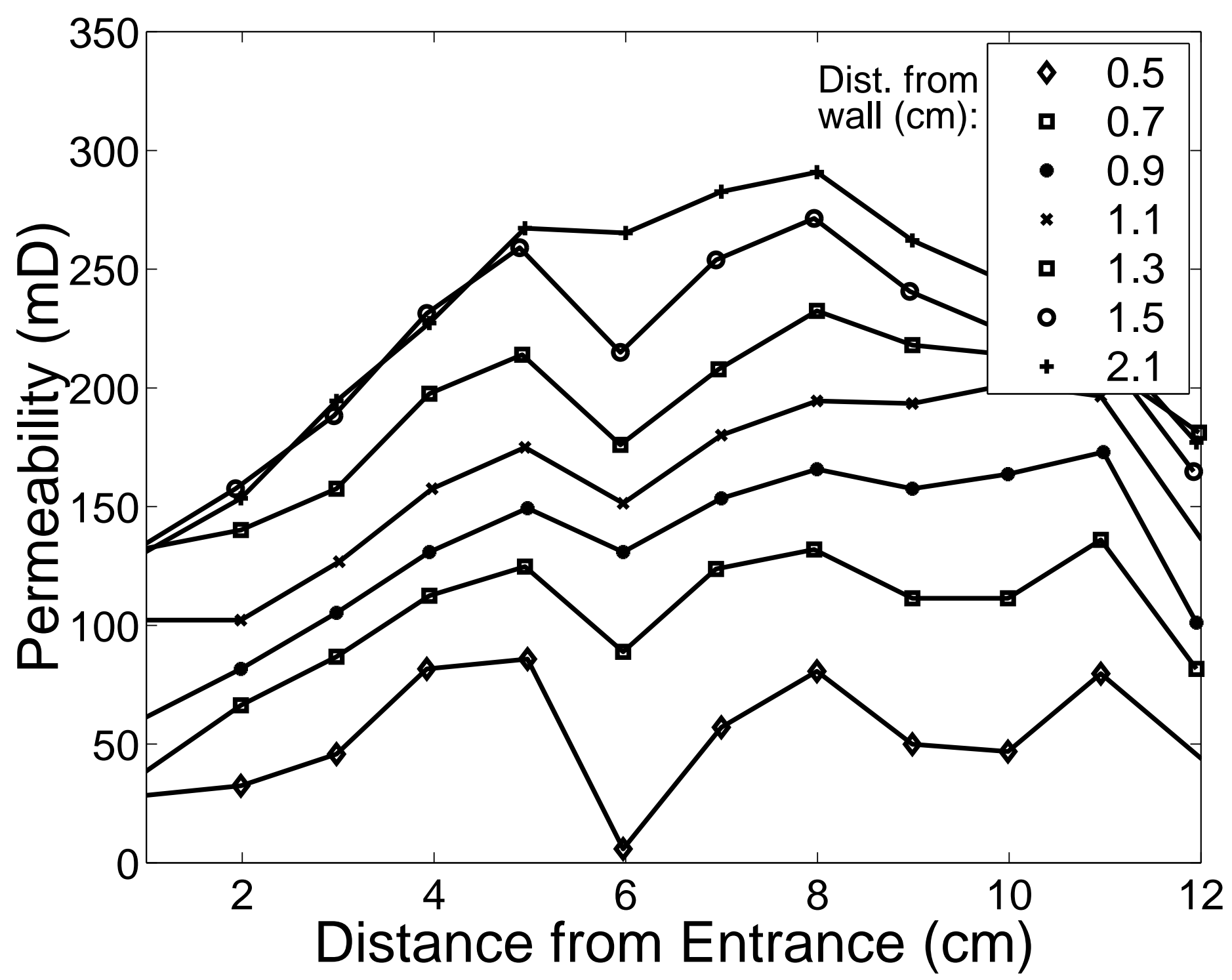

Figure 5: Permeability versus distance from entrance hole and from tunnel wall for 350 psi underbalance in Berea Sandstone as measured by Karacan and Halleck. ${ }^{22}$ 


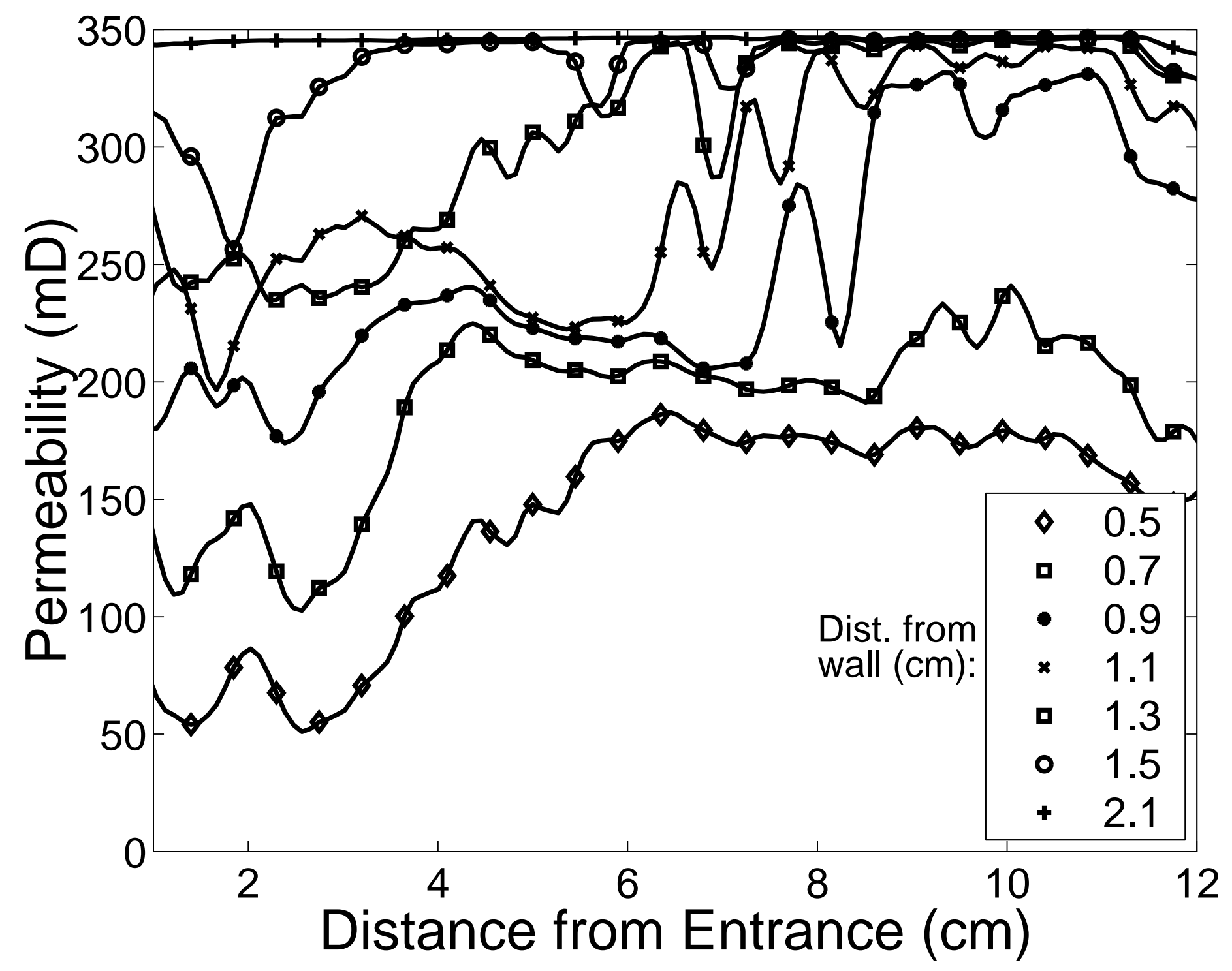

Figure 6: Permeability at the end of the hydrocode simulation versus distance from entrance hole and from tunnel wall with no fines. 


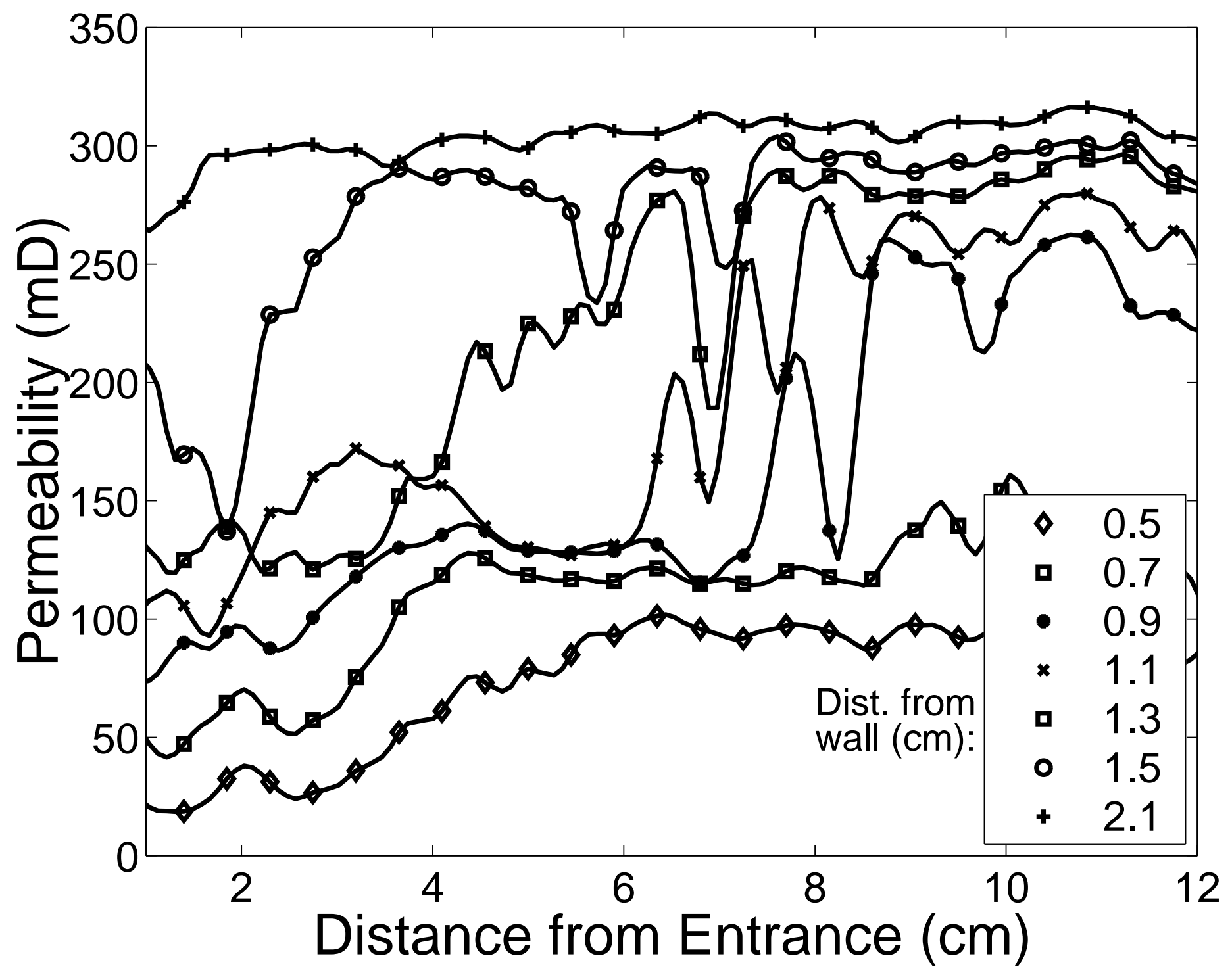

Figure 7: Permeability at the end of the hydrocode simulation versus distance from entrance hole and from tunnel wall with fines added and balanced conditions. 


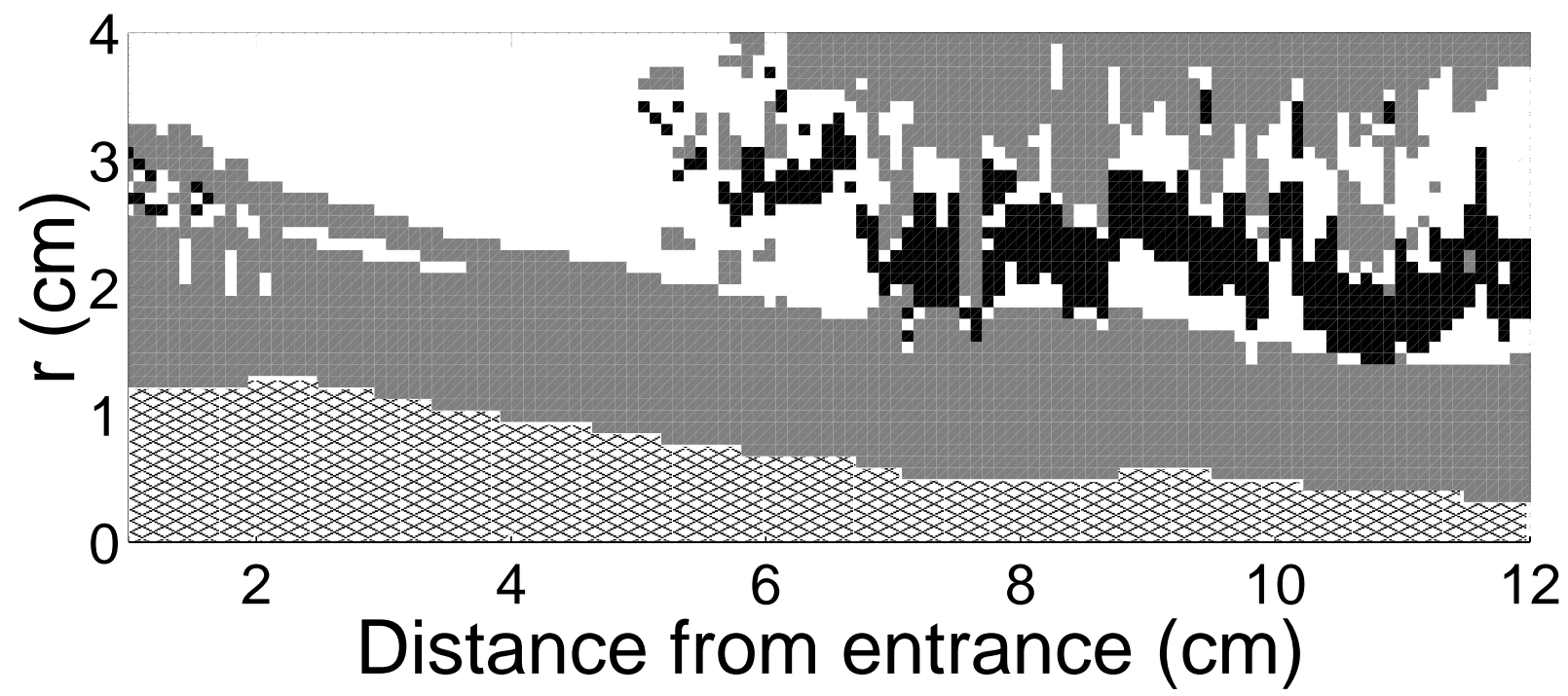

Figure 8: Two-dimensional map of the fractional permeability change due to 750 psi underbalance versus balanced conditions. Gray regions indicate an increase in permeability of $5 \%$ or more while black indicates a reduction of $5 \%$ or more. The crosshatch region indicates the extent of the tunnel. 


\section{0 psi Underbalance}
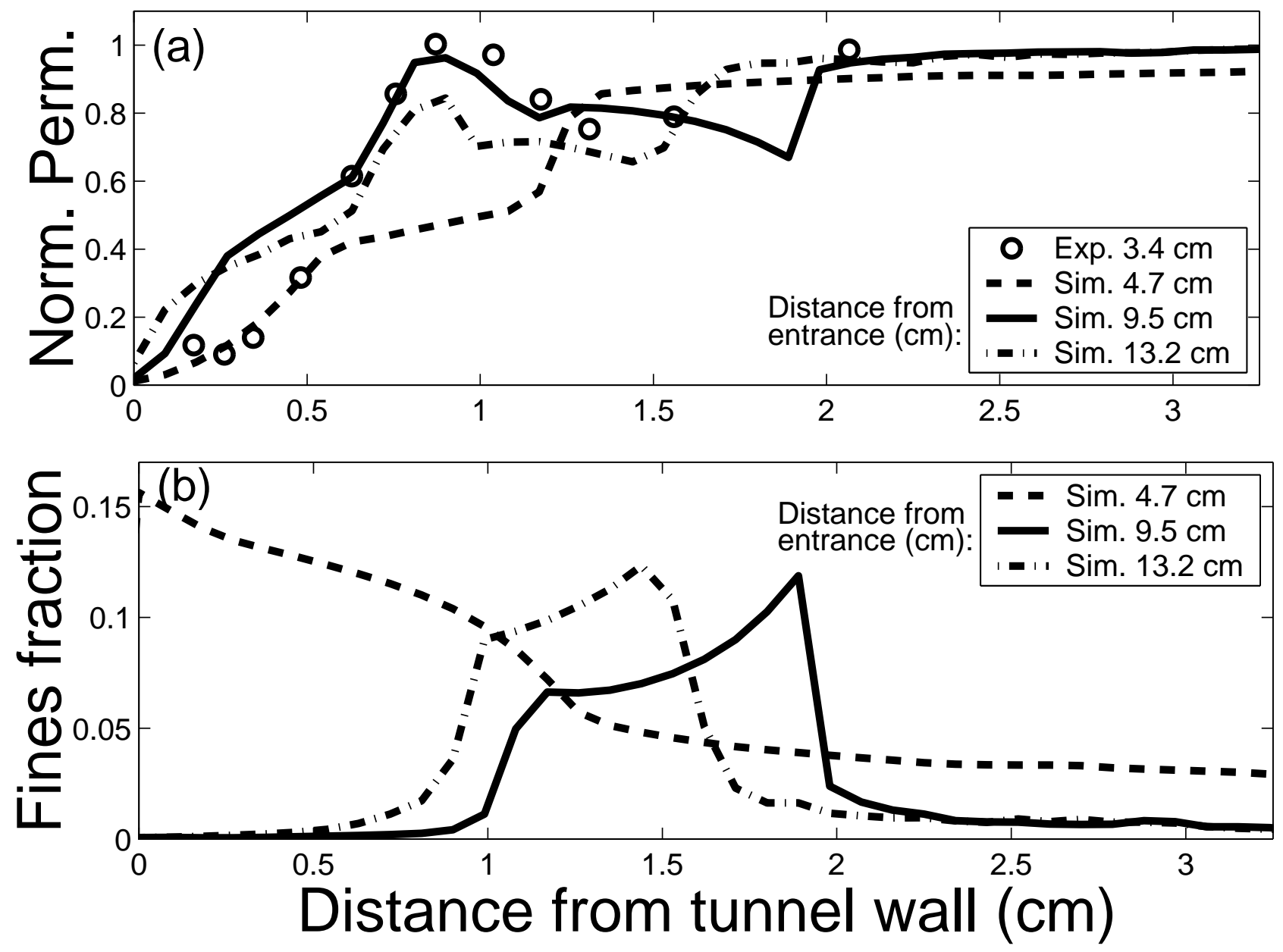

Figure 9: A comparison of experimentally measured permeability evolution with results from the fines migration simulator using initial conditions from the hydrocode. (a) Normalized permeability measured by Karacan and Halleck ${ }^{22}$ compared with simulation. (b) Simulated fines fraction. Closer to the tunnel entrance, the hydrocode over predicts the reduction in permeability, leading to lower flow rates and minimal clean up. 


\section{0 psi Underbalance}
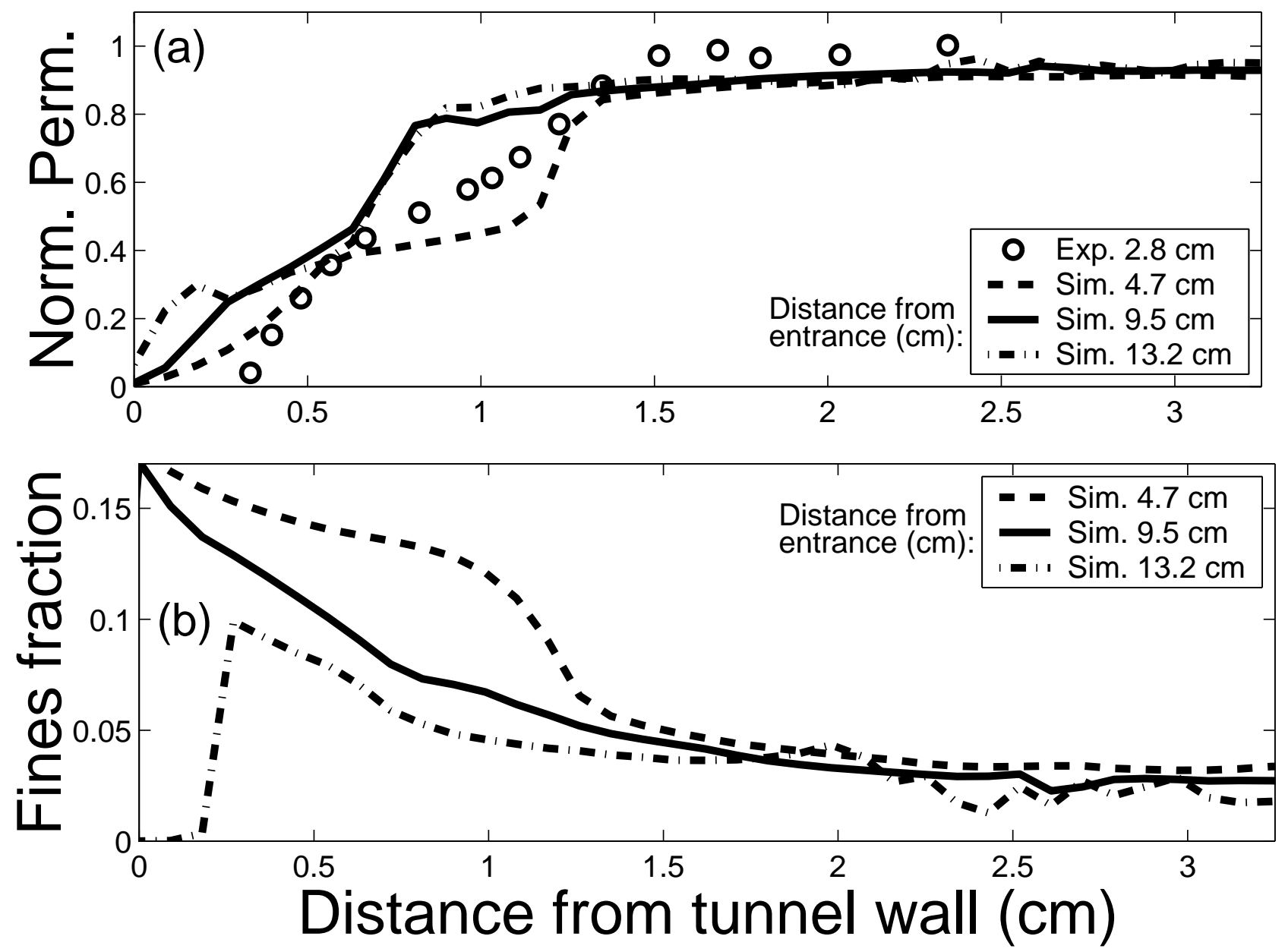

Figure 10: A comparison of experimentally measured permeability evolution with results from the fines migration simulator using

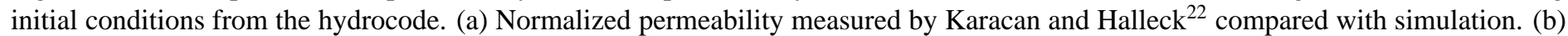
Simulated fines fraction. 